\title{
Intracellular iron uptake is favored in Hfe-KO mouse primary chondrocytes mimicking an osteoarthritis-related phenotype
}

Márcio Simão ${ }^{1,2,3^{*}}$, Paulo J. Gavaia ${ }^{2,3}$, António Camacho ${ }^{4}$, Graça

Porto $^{5,6,7}$, I. Jorge Pinto ${ }^{7 \dagger}$, Hang-Korng Ea ${ }^{8}$, M. Leonor

Cancela ${ }^{2,3,9 *}$

1-PhD Program in Biomedical Sciences, Department of Biomedical Sciences and Medicine, University of Algarve, Faro, Portugal

2-Centre of Marine Sciences (CCMAR), University of Algarve, Faro, Portugal

3-Department of Biomedical Sciences and Medicine (DCBM), University of Algarve, Faro, Portugal

4-Department of Orthopedics, Hospital de Cascais, Alcabideche, Portugal

5-Pathology and Molecular Immunology Department, Institute of Biomedical Sciences Abel Salazar, University of Porto, Porto, Portugal.

6-Hematology Service, Hospital de Santo António, Centro Hospitalar do Porto, Porto, Portugal

7- Instituto de Biologia Molecular e Celular (IBMC) and Instituto de Investigação e Inovação em Saúde (I3S), University of Porto, Porto, Portugal

8-Inserm U1132/ BIOSCAR, and Université Paris 7 Denis Diderot, Hôpital Lariboisière, Paris, France

9-Algarve Biomedical Centre (ABC) and Centre for Biomedical Research (CBMR), University of Algarve, Faro, Portugal

Keywords: Chondrocyte metabolism; HFE-Hemochromatosis; Hfe-KO; Iron toxicity; Osteoarthritis

*Corresponding authors: Márcio Simão (masimao@ualg.pt) and M Leonor Cancela (lcancela@ualg.pt)

$\dagger$ Deceased during the realization of this work 


\begin{abstract}
HFE-hemochromatosis is a disease characterized by a systemic iron overload phenotype mainly associated with mutations in the HFE protein (HFE) gene. Osteoarthritis (OA) has been reported as one of the most prevalent complications in HFEhemochromatosis patients but the mechanisms associated with its onset and progression remain incompletely understood. In this study, we have characterized the response to high iron concentrations of a primary culture of articular chondrocytes isolated from newborn Hfe-KO mice and compared the results to a similar experiment developed in cells from C57BL/6 (WT) mice. Our data provide evidences that both WT and Hfe-KO derived chondrocytes, when exposed to $50 \mu \mathrm{M}$ of iron, develop characteristics of an OA-related phenotype, such as an increased expression of metalloproteases, a decreased extracellular matrix production and a lower level of expression of aggrecan. In addition, Hfe-KO cells also showed an increased expression of $\mathrm{Mmp3}$, indicating an increased susceptibility to intracellular iron accumulation. Accordingly, upon treatment with $50 \mu \mathrm{M}$ of iron, these chondrocytes were found to preferentially differentiate towards hypertrophy with increased expression of collagen I, transferrin and downregulation of SRY (SexDetermining Region Y)-box containing gene 9 (Sox9). In conclusion, high iron exposure can compromise chondrocyte metabolism which, when simultaneously affected by an Hfe loss of function, appear to be more susceptible to the establishment of an OA-related phenotype.
\end{abstract}




\section{1-Introduction}

Articular cartilage is a highly specialized tissue, avascular and hypocellular, composed primarily of water and extracellular matrix produced by chondrocytes, the only cell type present in this tissue [1]. Chondrocytes are specialized cells responsible for the production of extracellular cartilage matrix (ECM) composed by several macromolecules including aggrecan and type II, IX and XI collagens, which are important for the maintenance of the cartilage properties including tensile strength and flexibility $[1,2]$.

Osteoarthritis (OA) is the most frequent adult joint disease and is characterized by structural and molecular modifications in subchondral bone, synovial membrane, muscle, ligament and cartilage, that ultimately lead to joint destruction [3-5]. Several factors contribute to OA development including mechanical overload, ageing, genetic background, obesity, metabolic syndromes and the presence of calcium-containing microcrystals in the joint. However its underlying physiopathology is still incompletely understood [3-5].

Hemochromatosis is an inherited metabolic disorder characterized by systemic iron overload and is associated to mutations in genes involved in iron metabolism [6, 7]. The most common gene affected is the HFE, encoding a protein that functions as an important sensor for systemic iron levels, the most prevalent HFE pathogenic mutation being the C282Y (p.Cys282Tyr) which results in the substitution of an adenine (A) for a cytosine (C), (NG_008720.2:g.10633G4A; NM_000410.3:c.845G4A), and individuals homozygotes for this mutation have an increased risk of developing iron overload. The association between OA and HFE-hemochromatosis was first described by Schumacher in 1964, who showed an increased prevalence of arthritis in those patients [8]. Since then, several studies have confirmed this observation [9-14], which suggested an association between elevated iron concentrations, HFE loss of function and articular cartilage integrity, however it was not clear which could be the main factor affecting cartilage metabolism. Recently, we have shown that Hfe-KO mice develop more severe knee OA than wild type (WT) mice after joint destabilization induced by partial meniscectomy [14], but the underlying molecular mechanisms remain unclear. Therefore, we have developed an in vitro approach to further investigate the molecular events occurring in chondrocytes exposed to high levels of ferric citrate. Primary cultures of articular chondrocytes derived from Hfe-KO mice were exposed to $50 \mu \mathrm{M}$ of ferric citrate in order to identify molecular factors and pathways involved in chondrocyte metabolism which 
may contribute to OA onset and progression and, simultaneously, characterize the effect of Hfe loss of function in the regulation of intracellular iron accumulation. In addition, we investigated the effect of iron toxicity on chondrocyte catabolism by evaluating (i) the expression of genes and its targets associated to extracellular matrix degradation, and (ii) the expression of differentiation markers like osteocalcin (Bglap2) and SRY (SexDetermining Region Y)-box containing gene 9 (Sox9) [15]. By comparing the responses of Hfe-KO and WT chondrocytes subjected to similar experimental conditions, we expected to identify possible susceptibility mechanisms associated with Hfe loss of function.

\section{2-Materials and Methods}

\section{1-Ethical statement}

All personnel involved in animal handling and experimentation received proper training (category B courses accredited by FELASA, the Federation of Laboratory Animal Science Associations). All experimental procedures involving animals followed the European Directive 2010/63/EU and the related guidelines (European Commission, 2014). The University of Algarve animal facility was licensed by Portuguese National Authority for Animal Health (DGAV), within Portuguese legislation (DL 113/2013) for animal experimentation and welfare.

\section{2-Biological models used in this study}

Animals were maintained under pathogen-free conditions in individually ventilated cages at the University of Algarve animal facility under a $12 \mathrm{hr}$ light/dark cycle and with access to water and food (SDS RM3A, iron content $161 \mathrm{mg} / \mathrm{kg}$ ) ad-libitum from weaning until euthanasia. The murine model of $\mathrm{HH}$ used in this study, Hfe-KO in a C57BL/6 background, was described by Bahram et al. (1999) [16] and backcrossed with C57BL/6 mice at IBMC. The Hfe-KO mice are homozygotes for a removal of exons 2 and 3 of the HFE gene, leading to loss of function of the Hfe protein [16, 17].

\section{3-WT and Hfe-KO primary chondrocytes isolation}


The method for isolation of primary chondrocytes was adapted from Gosset and colleagues (2008) [18]. In short, newborn mice (P6- day 6 after birth) were euthanized according with the recommendations of FELASA (Federation of European Laboratory Animal Science Associations). For isolation of articular cartilage, mouse anterior legs were dissected by removing the skin and soft tissues in order to isolate femoral heads and tibial plateau using a modular stereomicroscope (Leica MZ6). The articular cartilage pieces were submitted twice to 45 minutes incubation with $2 \mathrm{mg} / \mathrm{ml}$ collagenase D (Gibco) solution followed by an overnight digestion with $0.5 \mathrm{mg} / \mathrm{ml}$ of collagenase D (Gibco). All collagenase solutions were diluted in culture medium (Dulbecco's modified Eagle's medium (DMEM), (Gibco), supplemented with 1\% Penicillin/Streptomycin (250 $\mu \mathrm{g} / \mathrm{ml}$, Gibco) and 1\% Fungizone $(250 \mu \mathrm{g} / \mathrm{ml}$, Gibco).

Articular cartilage pieces were retrieved and passed sequentially through 25-, 10-, 5- and 2-ml pipettes and filtered through a $40 \mu \mathrm{m}$ cell strainer (Fisherbrand, nylon mesh) followed by $2000 \mathrm{~g}$ centrifugation for 10 minutes at room temperature. Cell pellets were resuspended in $10 \mathrm{ml}$ of culture medium supplemented with $10 \%$ Fetal Bovine Serum (FBS, Gibco). The chondrocyte suspension was counted in a hemocytometer and cell viability was determined by a quick trypan blue exclusion test ( $0.4 \%$, Sigma). The isolated chondrocytes were seeded at 25,000 cells $/ \mathrm{cm}^{2} /$ well onto a 12 well culture dish and cultures (Sarstedt) allowed to reach confluence. From this point onward FBS supplemented medium was changed every two days.

\section{4-Preparation of ferric citrate treatments}

To determine the ferric citrate concentrations to be applied in primary culture of chondrocytes, a preliminary assay with several ferric citrate concentrations was performed (data not shown) and two concentrations were chosen: $10 \mu \mathrm{M}$, which induced significant changes in iron metabolism markers, and $50 \mu \mathrm{M}$, which induced not only iron metabolism changes but also chondrocyte metabolism alterations. In addition, the iron concentrations chosen were within the physiological range identified for Hfe-KO mice, which, in the presence of iron overload, showed total iron concentrations in plasma ranging between 30 and $60 \mu \mathrm{M}[19,20]$.

Ferric citrate working solution was prepared from stock solutions of iron (III) chloride (10mM-Sigma-Aldrich), Trisodium citrate (100mM- Sigma-Aldrich) and 4-(2hydroxyethyl)-1-piperazineethanesulfonic acid (HEPES) (1M-Sigma-Aldrich). Iron 
citrate solution was applied to each well in dilutions of 1:33 in cell culture medium to reach final iron concentrations of $10 \mu \mathrm{M}([\mathrm{Fe}-\mathrm{Cit} 10 \mu \mathrm{M}])$ and $50 \mu \mathrm{M}([\mathrm{Fe}-\mathrm{Cit} 50 \mu \mathrm{M}])$. A negative control for iron presence was used by substituting the iron chloride solution by purified water (Sigma) [Na-Cit]. ferric citrate treatments were applied by adding it at each medium change, which occurred every two days, and evaluation for the effect of high ferric iron concentrations was done at days 7 ( 1 day after last treatment) and 10 (3 days after last treatment) of culture.

\section{5-Qualitative evaluation of extracellular cartilage matrix (ECM) production}

The evaluation of ECM production was done by staining with alcian blue the primary chondrocyte cultures, which had been proliferating for 10 days in 12 well plates (Stardsted).. Before staining the cells, medium was removed, cells were rinsed with Phosphate-Buffered Saline (PBS: $\mathrm{NaCl}(137 \mathrm{mM}), \mathrm{KCl}(2.7 \mathrm{mM}), \mathrm{Na}_{2} \mathrm{HPO}_{4} 2 \mathrm{H}_{2} \mathrm{O}(8.1$ $\mathrm{mM}), \mathrm{KH}_{2} \mathrm{PO}_{4}(1.47 \mathrm{mM})$, Sigma-Aldrich) and fixated in $70 \%$ ethanol (Emplura, Merck) for 30 min at $-20^{\circ} \mathrm{C}$. Then cells were rinsed $2 \mathrm{x}$ with PBS and incubated for at least 1 hour with $1 \mathrm{ml}$ of $0.5 \%$ alcian blue (8GX-Sigma-Aldrich) dissolved in $\mathrm{HCl}$ (1M-SigmaAldrich). After staining, each well was rinsed 2x with PBS and left in $1 \mathrm{ml}$ of PBS for analysis under a light-contrast microscope (Axiovert 25). Cell plates were photo-scanned and separated into three color channels (blue, green and red) for detection of pixel intensity of alcian blue staining using Image J. software v.151h (https://imagej.net/, RRID:SCR_003070) [21]. For each condition, three independent wells were evaluated and measured.

\section{6-Evaluation of expression of molecular markers}

RNA extractions of WT and Hfe-KO chondrocytes were done with High Pure RNA Isolation Kit (Roche) according with the manufacture instructions, which includes a DNase treatment during the procedure. For each condition tested, cells from three individual wells (Nucleon Delta Surface-Thermo scientific; $9.6 \mathrm{~cm}^{2}$ ) were pooled and used for each RNA extraction. RNA samples were quantified, assessed for puritity using a Nanodrop 1000 (Thermo Scientific) and for integrity using the Experion system (BioRad). Then, $1 \mu \mathrm{g}$ of RNA from each condition tested was reverse transcribed using $1 \mu \mathrm{L}$ of oligo(dT) adapter primer $(10 \mu \mathrm{M})$ and $1 \mu \mathrm{L}$ of M-MLV Reverse Transcriptase $(1 \mathrm{U} / \mu \mathrm{L}$,




performed using as template $2 \mu \mathrm{l}$ of $1: 10 \mathrm{cDNA}$ dilution $(0.01 \mu \mathrm{g})$ for each condition tested, $10 \mu 1$ of SsoFast Evagreen Taq supermix (BioRad), $0.6 \mu 1$ of either target gene primers $(300 \mathrm{nM})$ or housekeeping gene primers $(300 \mathrm{nM})$, and the final volume completed with purified RNase-free water (Sigma). Amplification by qPCR was performed in a Step One Plus Realtime PCR System (Applied Biosystems). Results are from five different experiments. To determine the levels of gene expression, all results were normalized against Gapdh levels of expression and relative expression was determined by the $\Delta \Delta \mathrm{Ct}$ method [21] using as control group for basal expression cells without treatment, unless stated otherwise. All primer sequences are described in the supplementary data (Table A1).

\section{7-Determination of intracellular iron}

The evaluation of intracellular iron concentrations was only done at 10 days of culture when extracellular matrix production was significantly altered, in order to characterize the corresponding intracellular iron status.

Primary chondrocytes (WT and Hfe-KO) were isolated and cultured for 10 days in the presence of ferric citrate treatments to achieve concentrations of $10 \mu \mathrm{M}$ or $50 \mu \mathrm{M}$ of iron, or in the absence of iron [Na-Cit]). Treatments were applied at each medium change. After 10 days, each cell culture plate was washed twice with PBS and treated with a solution of deferoxamine (DFO), (1mM-Sigma-Aldrich) in PBS for extracellular iron removal and then washed again with PBS. Quantification of intracellular iron concentrations was done with iron chelator Ferrozine (Sigma-Aldrich) using a method adapted from Riemer et.al. [22]. Briefly, $200 \mu \mathrm{L}$ of $\mathrm{NaOH}(50 \mathrm{mM}$, Sigma Aldrich) were added to each well and cell plates were subjected to agitation for $2 \mathrm{~h}$ under humidified atmosphere, after which cells were scrapped and $100 \mu \mathrm{L}$ of cell lysate recovered for iron quantification. To each $100 \mu \mathrm{L}$ of cell lysate were added $100 \mu \mathrm{L}$ of $\mathrm{HCl}(10 \mathrm{mM})$ followed by $100 \mu \mathrm{L}$ of iron release solution $\left(1: 1 ; 4.5 \% \mathrm{KMnPO}_{4}\right.$ (Sigma-Aldrich): $\left.\mathrm{HCl} 1.4 \mathrm{M}\right)$ and incubated for $2 \mathrm{~h}$ at $60^{\circ} \mathrm{C}$. After this, $30 \mu \mathrm{L}$ of freshly prepared iron detection solution (Ferrozine $(6.5 \mathrm{mM})$, Cuproine $(6.5 \mathrm{mM})$, Acetate ammonium $(2.5 \mathrm{M})$ and Ascorbic acid (1M); all from Sigma-Aldrich) was added to each sample and 30 minutes later $280 \mu \mathrm{L}$ of the mix was removed and absorbance measured in a microplate reader (Synergy4) at $550 \mathrm{~nm}$. The same procedure was done for calibration curve samples diluted in $\mathrm{HCl}$ $(10 \mathrm{mM})$. To normalize iron quantification the corresponding protein concentrations in 
cell lysate were determined using the Bio-Rad Protein assay kit (Bio-Rad) according with manufacture recommendations.

\section{8- Evaluation of articular cartilage integrity by OARSI score}

WT and Hfe-KO mice (male and female) knee articulations were collected after euthanasia and fixed for $24 \mathrm{~h}$ in $4 \%$ paraformaldehyde in PBS $\mathrm{pH} 7.4$, followed by decalcification with $0.5 \mathrm{M}$ Ethylenedinitrilotetraacetic acid (EDTA) in PBS pH 7.4 for 3 weeks. Samples were then dehydrated with graded alcohols, cleared with Xylol and included in paraffin, followed by $5 \mu \mathrm{m}$ sagittal sectioning in a rotary microtome (Microm HM340E, Germany) and stained with Safranin-O/Fast Green/Meyer's Hematoxylin. The evaluation was done in two sections per level and in three levels separated by $100 \mu \mathrm{m}$ each, starting at menisci separation. Two separate observers, blinded to the strain and type of intervention, graded the cartilage lesions using the semi-quantitative scoring system proposed by Glasson et al. 2010, also known as the OARSI scoring system for murine osteoarthritis. This system is based on the cartilage destruction extent, graded 0-6 depending on the depth of the lesion and on the percentage of the articular surface affected. The score for each knee was the sum of the scores from each of the three levels.

\section{9-Western blot analysis}

Isolated primary chondrocytes (WT and Hfe-KO) were maintained in culture and subject to iron citrate treatments ([Fe-Cit, $10 \mu \mathrm{M}]$ and [Fe-Cit, $50 \mu \mathrm{M}])$ applied at each medium change for 10 days, or not treated ([NT]) for cells of control condition. For protein extracts isolation, each well (independent triplicates for each condition) was washed with cold PBS and cells were lysed using $200 \mu$ l per well of lysis solution $(50 \mathrm{mM}$ Tris, $150 \mathrm{mM}$ sodium chloride, 1\% nonyl phenoxypolyethoxylethanol (NP-40), 10\% glycerol, $10 \mathrm{mM}$ magnesium chloride, $10 \mathrm{mM}$ sodium orthovanadate (all reagents from Sigma-Aldrich), and protease inhibitor cocktail (Roche) and mechanically removed using cell scrapers (Sarstedt) followed by centrifugation of each sample for $15 \min (15,000 \mathrm{~g})$. Protein content in each sample was quantified by the Bio-Rad Protein Assay (Bio-Rad) and $35 \mu \mathrm{g}$ of protein for each condition were fractioned in 4-12\% SDS/PAGE (Invitrogen) and transferred onto $0.45 \mu \mathrm{m}$ polyvinylidene difluoride (PVDF) membranes (Millipore, Billerica, MA, USA). Polyclonal anti-mouse rabbit antibodies were used for detection of MMP3 (1:500 dilution; Proteintech Group Cat\# 17873-1-AP), and for normalization of expression, beta-Actin (1:500 dilution; Santa Cruz Biotechnology Cat\# sc-47778), anti- 
rabbit IgG peroxidase conjugate (1:30,000 dilution; Sigma-Aldrich Cat\# R3155) and antimouse IgG peroxidase conjugate (1:30,000 dilution; Sigma-Aldrich Cat\# A9044) were used. Peroxidase chemiluminescent signals were detected using the Western Lightning ECL kit (Perkin Elmer, Waltham, MA, USA).

\subsection{0- In vivo ADAMTS5 and MMP3 imunohistochemistry detection}

ADAMTS5 and MMP3 detection by immunohistochemistry were evaluated in 5 $\mu \mathrm{m}$ sections from WT MNX and Hfe-KO MNX groups. The sections were dewaxed and rehydrated followed by epitope retrieval (for MMP3 with chondroitinase $0.1 \mathrm{UI} / \mathrm{mL}$, C3667-Sigma-Aldrich, and for ADAMTS5 with 10\% Trypsin-EDTA solution, SigmaAldrich), and then treated with 3\% hydrogen peroxide to block endogenous peroxidases for $10 \mathrm{~min}$. Next the sections were incubated for $30 \mathrm{~min}$ with blocking solution $(6 \%$ horse serum (Sigma-Aldrich) and 4\% BSA) prior to incubation with polyclonal rabbit antibodies against mouse MMP-3 (AB53015, Abcam at 1:100 in 3\% horse serum and 2\% BSA) and ADAMTS-5 (Ab39202, at 1:50 in 3\% horse serum and $2 \%$ BSA) at $4{ }^{\circ} \mathrm{C}$ overnight. The sections were next incubated with the secondary antibody (horseradish peroxidase-conjugated goat antibodies against rabbit IgG (Vector MP-7401)) at a 1:100 dilution and revelation done with DAB Kit SK4100 (Vector laboratories). Counterstaining was done with 1\% methyl green (Sigma-Aldrich), which stains hyaline cartilage tissues.

\subsection{1-Statistical analysis}

Unless stated otherwise, results are expressed as the mean and standard deviation (SD). Each group was evaluated for normality with Kolmogorov-Smirnov test and confirmed for application of parametric analysis. Comparisons of matrices of means in function of iron citrate treatments versus mice genotypes were done by Two-way ANOVA. Multiple comparisons in both statistical tests used were done by Tukey method with $p<0.05$. Indications of significance for multiple tests were subdivided into (a) and (b) for comparison within the same genotype: (a)- when differences in results were significant compared to iron citrate treatment control group ([Na-Cit]) and (b) when differences in results were significant compared to $10 \mu \mathrm{M}$ iron citrate treatment ([Fe-Cit 
$10 \mu \mathrm{M}]) ;(*)$ - Significance of Hfe-KO genotype relative to WT when subject to the same iron citrate treatments. For data where normality was not confirmed, Krustal-Wallis test was done with Dunn's post-hoc test for multiple comparison. For comparison of data where normality was confirmed, the One-way ANOVA was used with Tukey test for post-hoc multiple comparison with $\mathrm{p}<0.05$.

\section{3-Results}

\subsection{Hfe-KO primary chondrocyte cultures morphology and molecular phenotype}

Primary chondrocytes were isolated from the articular cartilage of the knee joint from Hfe-KO and WT newborn mice and its morphological, histological and molecular profiles analyzed. In terms of morphology, no significant differences were observed, with cells showing the typical hexagonal phenotype of chondrocytes (Supplementary figure S1-A). The expression of molecular markers for chondrocyte metabolism was determined in WT and Hfe-KO primary chondrocytes by qPCR. Both cells expressed similar levels of transcripts for collagens type I, II and X (Colla1, Col2a1, CollOal) and for aggrecan (Acan), with the expression of Col2al transcripts being predominant. Expression of transcription factor AP-2-alpha (Tfap2a), a negative marker of chondrocyte differentiation, was nearly absent in both cell cultures, as expected (Supplementary figure S1-B). Viability was assessed for both WT and Hfe-KO cells treated with $10 \mu \mathrm{M}$ and 50 $\mu \mathrm{M}$ of ferric citrate during $72 \mathrm{~h}$ and $120 \mathrm{~h}$. Chondrocyte viability was similar in both genotypes and was not affected by iron treatment (Supplementary figure S2). The results were confirmed in vivo (Figure 2) as Hfe-KO mice did not spontaneously develop an early OA phenotype. Results showed no significant lesions or loss of cartilage in Hfe-KO mice knee articulation with 12 months of age. In addition, accumulation of iron deposits was not observed in the articular cartilage, only in subchondral bone (Figure 2-C).

\section{2-Hfe-KO chondrocytes show imbalanced iron metabolism}

WT and Hfe-KO chondrocytes showed similar profiles for Slc40al and Fht gene expression in response to excess iron (10 and $50 \mu \mathrm{M}$ of ferric citrate exposure). Both Slc40al and Fht 1 were upregulated (Figure 1-A) with a significant increase observed in cells Hfe-KO relative to WT when exposed to $50 \mu \mathrm{M}$ of ferric citrate (Figure 1-A). In 
response to excess iron, Tfrc receptor was downregulated in WT but not in Hfe-KO cells (Figure 1-A), indicative of an intracellular iron transport inhibition for WT which was not observed in Hfe-KO chondrocytes. These results were confirmed by the anaysis of intracellular iron levels in WT and Hfe-KO chondrocytes at 10 days of incubation, when the effect of iron in ECM degradation was evident. The results showed a significant increase of intracellular iron in cells $\mathrm{Hfe}-\mathrm{KO}$ relative to WT subject to $50 \mu \mathrm{M}$ of ferric citrate (Figure 1-B). This accumulation of iron was not linearly correlated, which suggested that both WT and Hfe-KO chondrocytes were able to regulate iron entry, although less efficiently in Hfe-KO genotype. This is in agreement with results obtained when comparing the expression of iron transporters, $T f r 2$ and Slc39a14, in response to 10 $\mu \mathrm{M}$ and $50 \mu \mathrm{M}$ of ferric citrate. Both were downregulated in $50 \mu \mathrm{M}$-treated cells relative to those treated with $10 \mu \mathrm{M}$ (Figure 1-C). In addition, for both WT and Hfe-KO cells, Bmp6, the main iron metabolism regulator, showed a pathern of expression similar to those of iron transporters, being upregulated in response to $10 \mu \mathrm{M}$ treatment, but returning to control levels in the presence of $50 \mu \mathrm{M}$ treatment (Suplementary figure S3).

\section{4-Inflammatory and antioxidant response to increased iron concentrations}

Because inflammatory pathways have been associated to onset of OA phenotype, the expression of interleukin-1-beta (Il-1b) and interleukin-6 (Il-6) were evaluated in the WT and Hfe-KO chondrocytes treated with iron citrate, after 7 days in culture. No significant changes in the expression of $I l-1 b$ and $I l-6$ were observed at the analysed time points, (Supplementary figure S4). These results were confirmed for chondrocytes treated with $50 \mu \mathrm{M}$ at 10 days of incubation (data not showed). To evaluate the antioxidant response in this in vitro system, expression of Catalase $(\mathrm{Cat})$ and $\mathrm{Cu} / \mathrm{Zn}$ superoxide dismutase $(S o d)$ transcripts was analysed in WT and Hfe-KO cells. Both showed a significant increase in Cat expression in response to $50 \mu \mathrm{M}$ of ferric citrate treatments (Figure 3-A). In contrast, no differences were observed in the expression of Sod (data not shown). The expression of endothelial PAS domain-containing protein 1 (Epas1), also known as hypoxia-inducible factor 2-alpha (Hif-2-alpha), a transcription factor associated with hypoxia and antioxidative response and a catabolic regulator of cartilage destruction, showed a similar trend of expression, with higher expression levels observed under 50 $\mu \mathrm{M}$ treatment for both WT and Hfe-KO cells (Figure 3-B). 


\section{5-Effect of ferric citrate treatments on expression of chondrocyte metabolic markers}

The expression of three genes associated with chondrocyte catabolism ( $M m p 3$, Mmp13 and Adamts5) was evaluated. A similar pattern of gene expression was observed for Mmp13 and Adamts5, both in WT and Hfe-KO chondrocytes, with a clear upregulation always observed upon treatment with $50 \mu \mathrm{M}$ of iron (Figure 3-C). Expression of genes related to chondrocyte anabolism (Colla1, Cola10al and Acan) also showed, in each case, a similar pattern for both WT and Hfe-KO cells (Figure 4-A) indicating a similar mode of regulation in the presence $50 \mu \mathrm{M}$ of iron. We have also analysed the expression of Runx 2 but no significant differences were found under $10 \mu \mathrm{M}$ and $50 \mu \mathrm{M}$ treatments in both WT and Hfe-KO cells, (data not shown). Treatments with $50 \mu \mathrm{M}$ of ferric citrate also affected chondrocyte differentiation markers similarly for WT and Hfe-KO cells, with increased expression of osteocalcin (Bglap2) and transferrin (Trf) and a concomitant decrease in expression of SRY (Sex-Determining Region Y)-box containing gene 9 (Sox 9$)$, (Figure 4-B).

\section{6-High iron concentrations promoted a significant decrease in proteoglycan production}

As iron treatment appeared to be modulating in a similar way the expression of proteolytic enzymes and anabolic markers in both WT and Hfe-KO chondrocytes, we assessed whether it could modify the proteoglycan content of the cultures. Cells were stained with alcian blue and analysed after 7 and 10-day treatments with the 2 different concentrations of ferric citrate. Significant changes were only detected after 10 days. Both WT and Hfe-KO chondrocytes treated with $50 \mu \mathrm{M}$ of ferric citrate showed significant decrease in alcian blue staining compared to untreated chondrocytes (Figure 5-B). These results were in agreement with the changes observed in expression of genes associated to chondrocyte catabolism for the same iron concentrations $(50 \mu \mathrm{M}$ of ferric citrate, Figure 3), a result which was confirmed at the level of protein for MMP3 (Figure 5-C). In addition, an increase in protein expression was observed for ADAMTS5 and MMP3 in Hfe-KO samples when compared to WT (Figure 6). These results confirmed data previously described by our group in Camacho et al. (2016). 


\section{4-Discussion}

HFE protein is a known molecular player in iron metabolism, with impact on the regulation of intracellular iron concentrations and hepcidin expression in liver tissue [17, 23]. Attending to the increased incidence of osteoarthritis associated with HFEhemochromatosis [24-26], our primary objective was to investigate the effect of Hfe loss of function on chondrocyte metabolism. For that we have done a molecular characterization of WT and Hfe-KO primary chondrocyte cultures. We have first evaluated the effect of Hfe loss of function on cell phenotype and marker gene expression in primary cultures of chondrocytes from Hfe-KO mice and compared with data from WT derived cultures. Primary cultures of Hfe-WT or KO chondrocytes revealed their typical phenotype, comparable to previous reports $[18,27]$. As expected, the expression of Col2al was preponderant and those of Collal and Colloal were low (Supplementary figure S1-B), in agreement with previous works [18, 28]. In addition, Hfe-KO cells expressed Acan, a marker for extracellular matrix production [18], at levels similar to those found in WT cells, while there was no expression of Tfap2a, a negative marker of chondrocyte differentiation [28] (Supplementary figure S1-B). Thus, absence of Hfe did not alter the typical chondrocyte phenotype. These results suggest that the presence of a mutated Hfe gene alone was not sufficient to induce an OA-like phenotype in chondrocytes. Accordingly, we have shown in vivo that Hfe-KO mice did not develop OA (Figure2).

The absence of significant iron deposits in the Hfe-KO mice articular cartilage (Figure 2-C), suggests that an additional insult to articular cartilage is required to develop a pathological phenotype, in agreement with our previous data [14]. This was demonstrated in mice subject to meniscus destabilization, namely the aggravation of OA phenotype in Hfe-KO mice when compared with WT group (Figure 6-A), with evidences of significant iron accumulation in synovial tissues of Hfe-KO mice[14]. HFE effect on iron overload is connected with the downregulation of hepcidin expression (mainly specific to liver), which can favour dietary iron absorption and ferroportin iron exportation to plasma, resulting in systemic iron overload [29-31]. In addition, HFE loss of function can lead to increased intracellular iron absorption [32, 33]. The fact that articular cartilage is an avascular tissue [1] suggests that HFE can only contribute to OA progression if articular cartilage is exposed to blood, where it is possible to find both iron 
bound (TBI) and non-bound (NTBI) to transferrin. This is expected in HFEhemochromatosis patients following a trauma event and/or lesion in the articulation associated with bleeding and the corresponding increase in iron exposure.

Because it is known that HFE-hemochromatosis leads to a progressive iron overload with time [34], we designed experiments using concentrations close to physiological iron overload conditions $(50 \mu \mathrm{M})[19,20]$ to investigate if that would lead to the establishment of an OA-like phenotype. We submitted primary chondrocyte cultures (WT and Hfe-KO) to $10 \mu \mathrm{M}$ and $50 \mu \mathrm{M}$ of ferric citrate and results obtained showed that both WT and Hfe-KO chondrocytes developed an OA-like phenotype without mechanical or inflammatory stimulus. When cultured for 7 and 10 days under 10 $\mu \mathrm{M}$ and $50 \mu \mathrm{M}$ of ferric citrate, both Hfe-KO and WT cells showed significant changes in gene expression in response to treatment (Figure 1-A and Supplementary figure S6). The molecular profile was indicative of increased iron accumulation, which was more accentuated in Hfe-KO chondrocytes treated with $50 \mu \mathrm{M}$ of ferric citrate. These results were confirmed by the observed significant increase in the levels of intracellular iron concentrations (Figure 1-B). The upregulation of Fth1 and Slc40al (Figures 1-A and Supplementary figure S6) suggested an increase in the molecular response to intracellular iron in excess and an increase in iron export respectively, resulting from an attempt to reduce intracellular iron labile pool and contribute to iron detoxification, in agreement with previously published data [34-36].

Intracellular levels of iron accumulation did not present a linear correlation with levels of ferric citrate treatments (Figure 1-B), suggesting that intracellular iron regulation can be explained not only by an increase in Slc40al expression (Figures 1-A and Supplementary figure S6), to export excess iron, but also by the downregulation of Tfrc in WT chondrocytes (Figure 1-A) in agreement with previous data [37, 38]. In Hfe-KO chondrocytes, levels of intracellular iron were significantly higher than in WT cells when subject to $50 \mu \mathrm{M}$ of ferric citrate (Figure 1-B). This suggests a deregulation in the mechanism of iron import in those cells, probably related to the absence of a functional HFE protein, known to play an essential role in the regulation of iron transport into the cells by competing with TRF for TFRC binding [23]. If TRF binds to TFRC, it promotes the internalization of TFRC/TRF complex along with solute carrier family 11 member 2 (SLC11A2, also known as DMT-1) leading to intracellular iron absorption [39]. In this study, Tfrc was not significantly downregulated in Hfe-KO chondrocytes, in contrast to results in WT cells (Figure 1-A). Because SLC11A2 is a key player in intracellular iron 
uptake following TFRC/TRF internalization, the absence of a functional HFE could favour intracellular iron accumulation since it was previously shown that HFE/ $\beta 2$ microglobin complex is able to colocalize and bind with SLC11A2 and inhibit iron absorption [40]. However, regarding NTBI cellular uptake it was showed that SLC11A2 was not able to impair NTBI absorption in the liver enterocytes only transferrin bound iron (TBI) [41], contrarily to what was observed in enterocytes [36]. SLC11A2 is a ferrous iron transporter [39], and the treatment was done with ferric citrate, which suggests that the iron uptake may be done through TFRC/TRF internalization with the influence of HFE, unless $\mathrm{pH}$ and/or oxygen levels decrease. In addition, we have analyse the expression of Slc39a14, known NTBI intracellular transporter [42], was possible to observe that Slc39a14 was upregulated when cells were subject to $10 \mu \mathrm{M}$ of ferric citrate, however upon $50 \mu \mathrm{M}$ treatment Slc39a14 return to basal expression (Figure 1-C), suggesting a response to inhibit iron uptake and without the influence of HFE.

Since hepcidin expression was only detected at residual levels (data not shown), this led us to hypothesize that the significant differences observed in response to iron metabolism markers in Hfe-KO chondrocytes relative to WT should be primarily connected with the absence of HFE protein, responsible for regulating the entry of iron inside the cells $[36,43]$, and not with the regulation of ferroportin (SLC40A1) degradation by hepcidin $[34,44]$. The absence of an increased expression of inflammatory markers in both WT and Hfe-KO cells in this study was also previously observed during OA progression in Hfe-KO mice [14], and may be connected with primary response to stress, as also described previously in a blood induced joint damage study [45]. In that study, upregulation of Il-1b and Il-6 occurred only in the first hours after bleeding stimuli, and the levels of inflammatory markers decreased to basal levels after $24 \mathrm{~h}$, which could explain why we did not observe significant changes in the expression of pro-inflammatory markers, given the fact that we only analysed gene expression $24 \mathrm{~h}$ and $72 \mathrm{~h}$ after the last treatment. It will therefore be important in the future to study the inflammatory response in chondrocyte cultures in the first hours after ferric citrate treatment to understand the impact of inflammation in this context.

Increased ROS concentrations have been associated with OA phenotype [46, 47] which led us to evaluate indirect evidences of oxidative stress by analysing the expression of molecular markers associated with antioxidant response, like Cat, which showed to be upregulated in both WT and Hfe-KO cells (Figure 3-A). These results suggested that iron overload promoted an antioxidant response in chondrocytes [48, 49]. Another marker 
known to be sensitive to iron availability is Epasl, which is associated with hypoxia [50, 51] and one important catabolic regulator of cartilage destruction [52]. Our results show significant upregulation of Epas1 in response to the higher ferric citrate treatment (50 $\mu \mathrm{M})$ (Figure 3-B) suggesting that Epas1 should be contributing for the establishment of OA phenotype on both WT and Hfe-KO chondrocytes.

Bmp6, besides being one of the main regulators of hepcidin and of iron metabolism [53-55], has also been shown to be an inducer of chondrocyte proliferation and ECM production [56, 57]. The results for Bmp6 expression (supplementary figure S3) suggested that, after an initial response to iron increase $(10 \mu \mathrm{M})$ in WT and Hfe-KO chondrocytes, and upon higher iron concentrations, Bmp6 expression was restrained. This was indicative of a decrease in the SMAD 1, 5 and 8 pathway $[53,58]$, and reported to donwregulate Colloal and Sox9 and increase collal and bglap2 [59], which is in agreement with what we observed (Figure 4). Ferric citrate treatments had a significant and similar impact in the expression of Collal, Colloal and Acan in WT and Hfe-KO chondrocytes (Figure 4-A), as previouly observed and already associated with OA onset and progression in several in vivo and in vitro studies [14, 60-62].

In OA, the expression of Coll0al has been mostly shown to be increased [14, 60, 62], however downregulation of Col10a1 in human OA-associated articular chondrocytes has also been reported [61], similar to the gene expression pattern found in our study for Hfe-KO chondrocytes (Figure 4-A). Accordingly, upregulation of Bglap2 and downregulation of Sox9 in Hfe-KO chondrocytes (Figure 4-B) are in agreement with data reported previoulsy and shown to be associated with OA phenotypes [63-65], thus contributing to the significant impact of iron in chondrocyte differentiation towards hypertrophy. In addition, expression of the runt related transcription factor 2 (Runx2), an important transcription factor associated with chondrocytes hypertrophy [64], was not significantly changed by ferric citrate treatments (results not shown), whicht could explain the absence of Col10al upregulation in this context and suggests the existence of an alternative mechanism to induce an hypertrophy-like phenotype in WT and Hfe-KO chondrocytes subjet to $50 \mu \mathrm{M}$ of ferric citrate. Indeed, $\operatorname{Trf}$ expression was significantly upregulated (Figure 4-B). Since this increase in expression has not been directly associated with an iron increase [66], it could be associated with the acceleration of chondrocyte differentiation process towards an hypertrophy-like phenotype, an hypothesis that remains to be further explored, however this response could favour intracellular iron uptake through TRF/TFRC complex in the absence of a functional HFE. 
The evaluation of WT and Hfe-KO chondrocytes catabolism showed that expression of metalloproteases (Mmp3, Mmp13 and Adamts5) was significantly altered in the presence of a $50 \mu \mathrm{M}$ iron treatment (Figures 3-C, 5-C), in agreement with previously reported evidences for upregulation of metalloproteases upon $100 \mu \mathrm{M} \mathrm{FeCl}_{2}$ exposure [67]. In addition, extracellular matrix was significantly affected throughout progressive iron overload exposure, both in Hfe-KO and WT chondrocytes (Figure 5-A). These results were also confirmed by the in vivo increase in MMP3 and ADAMTS5 (Figure 6) and consequent decrease in methyl green staining (to detect hyaline cartilage [68]) in Hfe-KO mice subject to MNX relative to WT MNX animals, also observed in our previous work [14]. The significant upregulation of Mmp3 found in Hfe-KO chondrocytes suggests a possible synergistic effect between iron overload exposure and HFE loss of function. Altogether, these results are in agreement with published data since increase in MMP3 protein expression was previously associated to osteoarthritis phenotype and to extracellular matrix degradation [62,67] and suggest that iron overload conditions had a decisive impact in the catabolic activity of chondrocytes. The Hfe-KO chondrocyte genotype revealed increased susceptibility for deregulation of iron metabolism and related changes in gene expression, similarly to what may be happening during OA progression and with the association in vivo of mutations in Hfe with dysregulation of iron metabolism, which appear to contribute to increase OA phenotype [14]. However, results for WT chondrocytes showed that iron overload exposure was enough to produce an OA phenotype and ECM degradation with similar impact on gene expression markers. This finding suggested that HFE-hemochromatosis related OA establishment is conditioned by systemic iron overload produced by the impact of Hfe loss of function on liver hepcidin expression [17] and on chondrocyte metabolism, which can become relevant if articular cartilage is exposed to iron overload conditions attending to its role on the regulation of intracellular iron import [17, 23].

The exposure of WT and Hfe-KO chondrocytes to ferric citrate loads favoured iron accumulation and the development of an OA-similar phenotype, which is in agreement to what was described previously with the identification of iron deposits in the articular cartilage and synovial membrane of HFE-hemochromatosis patients and cartilage associated degradation [69-71]. Iron deposits were also detected in thalassemia patients articulation [72], suggesting the putative toxic effect of iron overload inside articulations. Epidemiology studies report high prevalence of OA associated HFEhemochromatosis in patients averaging 60 years of age, with a strong association between 
transferrin saturation and serum ferritin concentrations [26, 73]. Evidences showed that iron overload should play an important role on OA progression in HFE-hemochromatosis patients $[14,26]$. In addition, these patients showed higher susceptibility for the prevalence of OA when compared with non-HFE-hemochromatosis patients [74], which suggests additional susceptibility beyond systemic iron overload. Recently, it was reported a case were an HFE-hemochromatosis patient showed an early onset of knee OA (since he was 18 years old) [75]. The patient systemic iron parameters were considered normal even with constant OA related complains, however before the patient underwent bilateral knee replacement, significant iron deposits were observed in the knee synovial membrane [75], which may suggest a susceptibility associated with iron accumulation in synovium. Accordingly, the absence of HFE in cells cytoplasmatic membrane as consequence of $\mathrm{pC} 282 \mathrm{Y}$ substitution [76] were previously shown to favor intracellular iron accumulation [33]. In addition, attending that HFE is a protein belonging to the major histocompatibility complex (MHC-I) family, we cannot exclude that OA associated HFEhemochromatosis could also be related with a possible immune response to the absence of pC282Y HFE in cytoplasmic membrane [77]. There is also a report in which hand osteoarthritis prevalence is increased in heterozygotes (pC282Y) [11], however a recent study showed no significand differences between the prevalence of OA in pC282Y heterozygotes compared to general population [78]. Therefore, further studies regarding HFE recognition by the immune system are required.

In conclusion, exposure of WT and Hfe-KO chondrocyte cultures to high iron concentrations promoted the establishment of an OA-like phenotype suggesting that high levels of iron can contribute to the progression of OA associated with HFEhemochromatosis. In addition, results suggest that Hfe loss of function can contribute to promote an increase in intracellular iron accumulation in primary chondrocytes. However, this study cannot exclude the hypothesis that the onset of OA associated with HFE-hemochromatosis could be related with acute immune responses, even if the levels of inflammation are not comparable with those observed in chronic inflammation diseases like rheumatoid arthritis [70]. We propose that, upon articular lesion and/or trauma, patients showing systemic iron overload can present a degradation of articular cartilage associated with an increase in osteoarthritis progression. Our study does not take into account possible interactions between articular cartilage and synovial tissues since, accordingly with several reports, synovial membrane presents high levels of iron deposits in HFE-hemochromatosis [70, 75], which we also observed previously in Hfe-KO mice 
with aggravated OA progression [14]. Additional studies should be made regarding this possible interaction and the onset of OA in HFE-hemochromatosis.

\section{References}

[1] Triche, R. (2013) Overview of cartilage biology and new trends in cartilage stimulation. Foot Ankle Clin N Am 18:1-12.

[2] Staines, K.A., Pollard, A.S., McGonnell, I.M., Farquharson, C., Pitsillides, A.A. (2013) Cartilage to bone transitions in health and disease. J Endocrinol 219(1):112.

[3] Goldring, S.R., Goldring, M.B. (2016) Changes in the osteochondral unit during osteoarthritis: structure, function and cartilage-bone crosstalk. Nat Rev Rheumatol 12:632-644.

[4] Malfait, A.M. (2016) Osteoarthritis year in review 2015 : biology. Osteoarthr Cartil 24(1):21-26.

[5] Wei, Y., Bai, L. (2016) Recent advances in the understanding of molecular mechanisms of cartilage degeneration, synovitis and subchondral bone changes in osteoarthritis. Connect Tissue Res 57(4):245-61.

[6] Zaloumis, S.G., et al. (2014) The natural history of HFE simple heterozygosity for C282Y and H63D: a prospective twelve year study. J Gastroenterol Hepatol 30:1-22.

[7] Pietrangelo, A. (2010) Hereditary hemochromatosis: Pathogenesis, diagnosis, and treatment. Gastroenterology 139(2):393-408.

[8] Schumacher, R.H.J. (1964) Hemochromatosis and Arthritis. Arthritis Rheum 7(1):348-356.

[9] Carroll, G.J., Breidahl, W.H., Bulsara, M.K., Olynyk, J.K. (2011) Hereditary hemochromatosis is characterized by a clinically definable arthropathy that correlates with iron load. Arthritis Rheum 63(1):286-94.

[10] Carroll, G.J., Breidahl, W.H., Olynyk, J.K. (2012) Characteristics of the 
arthropathy described in hereditary hemochromatosis. Arthritis Care Res (Hoboken) 64(1):9-14.

[11] Ross, J., et al. (2003) Association of heterozygous hemochromatosis C282Y gene mutation with hand osteoarthritis. Acta Paediatr 30:121-5.

[12] Dallos, T., et al. (2013) Idiopathic hand osteoarthritis vs haemochromatosis arthropathy--a clinical, functional and radiographic study. Rheumatology 52(5):910-915.

[13] Guggenbuhl, P., Brissot, P., Loréal, O. (2011) Haemochromatosis: The bone and the joint. Best Pract Res Clin Rheumatol 25(5):649-664.

[14] Camacho, A., et al. (2016) Iron overload in a murine model of hereditary hemochromatosis is associated with accelerated progression of osteoarthritis under mechanical stress. Osteoarthr Cartil 24(3):494-502.

[15] Goldring, M.B. (2012) Chondrogenesis, chondrocyte differentiation, and articular cartilage metabolism in health and osteoarthritis. Ther Adv Musculoskelet Dis 4(4):269-285.

[16] Bahram, S., et al. (1999) Experimental hemochromatosis due to MHC class I HFE deficiency: immune status and iron metabolism. Proc Natl Acad Sci U S A 96(23):13312-13317.

[17] Feder, J.N., et al. (1996) A novel MHC class I-like gene is mutaded in patients with hereditary haemochromatosis. Nat Genet 14(3):353-6.

[18] Gosset, M., Berenbaum, F., Thirion, S., Jacques, C. (2008) Primary culture and phenotyping of murine chondrocytes. Nat Protoc 3(8):1253-1260.

[19] Trinder, D., Olynyk, J.K., Sly, W.S., Morgan, E.H. (2002) Iron uptake from plasma transferrin by the duodenum is impaired in the Hfe knockout mouse. Proc Natl Acad Sci U S A 99(8):5622-6.

[20] Zhou, X.Y., et al. (1998) HFE gene knockout produces mouse model of hereditary hemochromatosis. ProcNatlAcadSciUSA 95(5):2492-2497.

[21] Pfaffl, M.W. (2001) A new mathematical model for relative quantification in real-time RT-PCR. 29(9):16-21.

[22] Riemer, J., Hoepken, H.H., Czerwinska, H., Robinson, S.R., Dringen, R. (2004) Colorimetric ferrozine-based assay for the quantitation of iron in cultured cells. Anal Biochem 331(2):370-375.

[23] Feder, J.N., et al. (1998) The hemochromatosis gene product complexes with the transferrin receptor and lowers its affinity for ligand binding. Proc Natl Acad Sci 


\section{U S A 95(4):1472-7.}

[24] Elmberg, M., Hultcrantz, R., Simard, J.F., Carlsson, Å., Askling, J. (2013) Increased risk of arthropathies and joint replacement surgery in patients with genetic hemochromatosis: A study of 3,531 patients and their 11,794 first-degree relatives. Arthritis Care Res 65(5):678-685.

[25] Carroll, G.J., Breidahl, W.H., Jazayeri, J. (2009) Confirmation of two major polyarticular osteoarthritis (POA) phenotypes - differentiation on the basis of joint topography. Osteoarthr Cartil 17(7):877-881.

[26] Camacho, A., et al. (2015) Effect of C282Y genotype on self-reported musculoskeletal complications in hereditary hemochromatosis. PLoS One 10(3): $1-8$.

[27] Munirah, S., Samsudin, O.C., Aminuddin, B.S., Ruszymah, B.H.I. (2010) Expansion of human articular chondrocytes and formation of tissue-engineered cartilage: A step towards exploring a potential use of matrix-induced cell therapy. Tissue Cell 42(5):282-292.

[28] Huang, Z., Xu, H., Sandell, L. (2004) Negative regulation of chondrocyte differentiation by transcription factor AP-2alpha. J Bone Miner Res 19(2):245255.

[29] Ganz, T., Nemeth, E. (2012) Hepcidin and iron homeostasis. Biochim Biophys Acta - Mol Cell Res 1823(9):1434-1443.

[30] Kent, P., et al. (2015) Hfe and Hjv exhibit overlapping functions for iron signaling to hepcidin. J Mol Med (Berl) 93(5):489-98.

[31] Wu, X.G., et al. (2014) HFE interacts with the BMP type I receptor ALK3 to regulate hepcidin expression. Blood 124(8):1335-1343.

[32] Barton, J.C., Edwards, C.Q., Acton, R.T. (2015) HFE gene: Structure, function, mutations, and associated iron abnormalities. Gene 574(2):179-192.

[33] Chua, A.C.G., et al. (2008) The role of Hfe in transferrin-bound iron uptake by hepatocytes. Hepatology 47(5):1737-1744.

[34] Brissot, P., Loréal, O., Loreal, O. (2015) Iron metabolism and related genetic diseases: a cleared land, keeping mysteries. J Hepatol 64:505-515.

[35] Gozzelino, R., Arosio, P. (2016) Iron homeostasis in health and disease. Int J Mol Sci 17(130):1-14.

[36] Brissot, P., Ropert, M., Le Lan, C., Loréal, O. (2012) Non-transferrin bound iron: A key role in iron overload and iron toxicity. Biochim Biophys Acta - Gen Subj 
1820(3):403-410.

[37] Herbison, C.E., et al. (2009) The role of transferrin receptor 1 and 2 in transferrin-bound iron uptake in human hepatoma cells. Am J Physiol Cell Physiol 297:1567-1575.

[38] Lok, C.N., Loh, T.T. (1998) Regulation of transferrin function and expression: Review and update. Biol Signals Recept 7(3):157-178.

[39] Montalbetti, N., Simonin, A., Kovacs, G., Hediger, M.A. (2013) Mammalian iron transporters : Families SLC11 and SLC40 q. Mol Aspects Med 34:270-287.

[40] Arredondo, M., et al. (2006) Apical distribution of HFE - b 2-microglobulin is associated with inhibition of apical iron uptake in intestinal epithelia cells. BioMetals 19:379-388.

[41] Wang, C., Knutson, M.D. (2013) Hepatocyte divalent metal-ion transporter-1 is dispensable for hepatic iron accumulation and non-transferrin-bound iron uptake in mice. Hepatology 58(2):788-798.

[42] Pinilla-Tenas, J.J., et al. (2011) Zip14 is a complex broad-scope metal-ion transporter whose functional properties support roles in the cellular uptake of zinc and nontransferrin-bound iron. AJP Cell Physiol 301(4):C862-C871.

[43] Wang, J., Pantopoulos, K. (2011) Regulation of cellular iron metabolism. Biochem J 434(3):365-381.

[44] Hentze, M.W., Muckenthaler, M.U., Galy, B., Camaschella, C. (2010) Two to tango: regulation of mammalian iron metabolism. Cell 142(1):24-38.

[45] Sen, D., et al. (2013) Nuclear factor (NF)-kB and its associated pathways are major molecular regulators of blood-induced joint damage in a murine model of hemophilia. J Thromb Haemost 11(2):293-306.

[46] Yudoh, K., et al. (2005) Potential involvement of oxidative stress in cartilage senescence and development of osteoarthritis: oxidative stress induces chondrocyte telomere instability and downregulation of chondrocyte function. Arthritis Res Ther 7(2):R380-91.

[47] Hooiveld, M., Roosendaal, G., van den Berg, H., Bijlsma, J., Lafeber, F. (2003) Haemoglobin-derived iron-dependent hydroxyl radical formation in bloodinduced joint damage: An in vitro study. Rheumatology 42(6):784-790.

[48] Lepetsos, P., Papavassiliou, A.G. (2016) ROS / oxidative stress signaling in osteoarthritis. Biochim Biophys Acta 1862(4):576-591.

[49] Theriot, C.A., Westby, C.M., Morgan, J.L.L., Zwart, S.R., Zanello, S.B. (2016) 
High dietary iron increases oxidative stress and radiosensitivity in the rat retina and vasculature after exposure to fractionated gamma radiation. npj Microgravity 2(14):1-9.

[50] Loboda, A., Jozkowicz, A., Dulak, J. (2010) HIF-1 and HIF-2 transcription factors similar but not identical. Mol Cells 29(5):435-442.

[51] Muckenthaler, M.U., Galy, B., Hentze, M.W. (2008) Systemic iron homeostasis and the iron-responsive element/iron-regulatory protein (IRE/IRP) regulatory network. Annu Rev Nutr 28:197-213.

[52] Yang, S., et al. (2010) Hypoxia-inducible factor-2alpha is a catabolic regulator of osteoarthritic cartilage destruction. Nat Med 16(6):687-693.

[53] Corradini, E., et al. (2011) Iron regulation of hepcidin despite attenuated Smad 1,5,8 signaling in mice without transferrin receptor 2 or Hfe. Gastroenterology 141(5):1907-14.

[54] Corradini, E., et al. (2009) Bone morphogenetic protein signaling is impaired in an HFE knockout mouse model of hemochromatosis. Gastroenterology 137(4):1489-97.

[55] Silva, B., Faustino, P. (2015) An overview of molecular basis of iron metabolism regulation and the associated pathologies. Biochim Biophys Acta 1852(7):13471359.

[56] Bobacz, K., et al. (2003) Expression of bone morphogenetic protein 6 in healthy and osteoarthritic human articular chondrocytes and stimulation of matrix synthesis in vitro. Arthritis Rheum 48(9):2501-2508.

[57] Grimsrud, C.D., et al. (1999) BMP-6 Is an Autocrine Stimulator of Chondrocyte Differentiation. $J$ Bone Miner Res 14(4):475-482.

[58] Kautz, L.L., et al. (2008) Iron regulates phosphorylation of Smad1/5/8 and gene expression of Bmp6, Smad7, Id1, and Atoh8 in the mouse liver. Blood 112(4):1503-1509.

[59] Retting, K.N., Song, B., Yoon, B.S., Lyons, K.M. (2009) BMP canonical Smad signaling through Smad1 and Smad5 is required for endochondral bone formation. Development 136:1093-1104.

[60] Bateman, J.F., et al. (2013) Transcriptomics of wild-type mice and mice lacking adamts-5 activity identifies genes involved in osteoarthritis initiation and cartilage destruction. Arthritis Rheum 65(6):1547-1560.

[61] Brew, C.J., Clegg, P.D., Boot-Handford, R.P., Andrew, J.G., Hardingham, T. 
(2010) Gene expression in human chondrocytes in late osteoarthritis is changed in both fibrillated and intact cartilage without evidence of generalised chondrocyte hypertrophy. Ann Rheum Dis 69(1):234-40.

[62] Lorenz, H., Richter, W. (2006) Osteoarthritis: Cellular and molecular changes in degenerating cartilage. Prog Histochem Cytochem 40(3):135-163.

[63] Bleil, J., et al. (2015) Cartilage in facet joints of patients with ankylosing spondylitis (AS) shows signs of cartilage degeneration rather than chondrocyte hypertrophy: implications for joint remodeling in AS. Arthritis Res Ther 17(1):170.

[64] Van der Kraan, P.M., Van den Berg, W.B. (2012) Chondrocyte hypertrophy and osteoarthritis: Role in initiation and progression of cartilage degeneration? Osteoarthr Cartil 20(3):223-232.

[65] Lee, M.S., et al. (2009) Evaluation of differentially expressed genes by shear stress in human osteoarthritic chondrocytes in vitro. Chang Gung Med J 32(1):42-50.

[66] Zakin, M.M. (1992) Regulation of transferrin gene expression. FASEB J 6(14):3253-8.

[67] Kim, J.H., et al. (2014) Regulation of the catabolic cascade in osteoarthritis by the zinc-ZIP8-MTF1 axis. Cell 156(4):730-743.

[68] Baker, J.R., Williams, E.G.M. (1965) The use of methyl green as a histochemical reagent. $Q J$ Microsc Sci $\mathbf{s 3 - 1 0 6 ( 7 3 ) : 3 ~ L P ~ - ~} 13$.

[69] Axford, J.S., et al. (1991) Hip arthropathy in genetic hemochromatosis. Radiographic and histologic features. Arthritis Rheum 34(3):357-361.

[70] Heiland, G.R., et al. (2010) Synovial immunopathology in haemochromatosis arthropathy. Ann Rheum Dis 69(6):1214-1219.

[71] Schumacher, H.R. (1982) Articular cartilage in the degenerative arthropathy of hemochromatosis. Arthritis Rheum 25(12):1460-1468.

[72] Economides, C.P., Soteriades, E.S., Hadjigavriel, M., Seimenis, I., Karantanas, A. (2013) Iron deposits in the knee joints of a thalassemic patient. Acta Radiol Short Reports 2(1):1-5.

[73] Richette, P., Ottaviani, S., Vicaut, E., Bardin, T. (2010) Musculoskeletal complications of hereditary hemochromatosis: A case-control study. J Rheumatol 37(10):2145-2150.

[74] Sandhu, K., et al. (2018) Phenotypic analysis of hemochromatosis subtypes 
reveals variations in severity of iron overload and clinical disease. Blood 132(1):101-110.

[75] Chehade, S., Adams, P.C. (2019) Severe Hemochromatosis Arthropathy in the Absence of Iron Overload. Hepatology 0(0):2018-2019.

[76] Pinto, J.P., Ramos, P., de Sousa, M. (2007) Overexpression of HFE in HepG2 cells reveals differences in intracellular distribution and co-localization of wtand mutated forms. Blood Cells, Mol Dis 39(1):75-81.

[77] Reuben, A., Chung, J.W., Lapointe, R., Santos, M.M. (2017) The hemochromatosis protein HFE 20 years later: An emerging role in antigen presentation and in the immune system. Immun Inflamm Dis 5(3):218-232.

[78] Pilling, L.C., et al. (2019) Common conditions associated with hereditary haemochromatosis genetic variants: Cohort study in UK Biobank. BMJ 364:112.

\section{Acknowledgements}

We want to dedicate this work to the memory of I. Jorge Pinto, co-author in this study who unfortunately was deceased during the realization of this work.

We thank Caroline Marty at INSERM 1132 Bioscar, Hôpital Lariboisière for her technical expertise with histochemical techniques.

\section{Funding}

This research was supported in part by National Funds through the Portuguese Science and Technology Foundation (FCT), under the project UID/Multi/04326/2019 (CCMAR) and from the operational programs CRESC Algarve 2020 and Compete 2020 through project EMBRC.PT Alg-01-0145-FEDER-022121 and Norte-01-0145-FEDER000012 - "Structured program on bioengineered therapies for infectious diseases and tissue regeneration”. M. Simão was supported by a $\mathrm{PhD}$ fellowship from the Portuguese Foundation for Science and Technology (FCT) with the reference SFRH/BD/77056/2011.

\section{Conflict of interest declaration}


The authors have no conflict of interest do disclose.

\section{Figures legends}

Figure 1- Expression of genes associated with iron metabolism in Hfe-KO and WT chondrocytes cultured under iron overload conditions (Genes: Solute Carrier Family 40 Member 1 (Slc40a1), also known as ferroportin, Ferritin Heavy Chain 1 (Fth1), solute carrier family 39 (zinc transporter) member 14 (Slc39a14), Transferrin receptor 1 (Tfrc) and Transferrin receptor 2 (Tfr2)). Cells were cultured for 7 days in the presence of either $10 \mu \mathrm{M}$ or $50 \mu \mathrm{M}$ of ferric citrate, or vehicle ([Na-Cit]). Results shown correspond to relative expression normalized with Gapdh from $\mathrm{n}=5$ pools of three cell culture wells $\left(9.6 \mathrm{~cm}^{2}\right)$ for each genotype (WT and Hfe-KO). Each pool corresponded to an independent experiment; A)-Intracellular iron markers (Slc40a1, Fth1 and Tfrc), B)- Correlation between measured intracellular iron concentrations and levels of ferric citrate treatments applied to WT and Hfe-KO chondrocytes. Each condition corresponded to data from $\mathrm{n}=3$ samples and were expressed as mean $+/$ - standard deviation (SD). (C)- Iron transporters (Tfr2, Slc39a14); Statistical analysis was done by Two-way ANOVA, followed by Tukey multiple comparison test with $\mathrm{p}<0.05$. Statistical significance: (a)- compared to control [Na-Cit]; (b)- compared to [Fe-Cit $10 \mu \mathrm{M}]$ ); (*)- comparison between WT and Hfe-KO cells subject to [Fe-Cit $50 \mu \mathrm{M}]$.

Figure 2-Articular cartilage integrity analysis and iron status in $\mathrm{Hfe}-\mathrm{KO}$ mice AEvaluation of knee articular cartilage integrity through OARSI score of WT and Hfe-KO mice with 12 months of age (male $(n=7)$ and female $(n=4))$ and examples of articular 
cartilage phenotype in $5 \mu \mathrm{m}$ sagittal sections of WT and $\mathrm{Hfe}-\mathrm{KO}$ mice stained with Haematoxylin-Fast Green-Safranin-O staining. (*) Statistical significance with $p<0.05$. Comparison was made T-test within each genotype B- Total serum iron quantification from WT and Hfe-KO male mice with 12 months of age. C- Perls staining of undecalcified tissues sagittal sections $(5 \mu \mathrm{m})$ of articular cartilage included in Methyl methacrylate (MMA). Iron deposition shown by dark blue staining.

Figure 3- Expression of genes associated with antioxidant response, hypoxia and markers associated with chondrocyte catabolism. Hfe-KO and WT chondrocytes were subjected to treatments for 7 days with either $10 \mu \mathrm{M}$ or $50 \mu \mathrm{M}$ of ferric citrate, or vehicle ([Na-Cit]). Results were normalized with Gapdh from n=5 pools of three cell culture wells $\left(9.6 \mathrm{~cm}^{2}\right)$ for each genotype (WT and Hfe-KO). Each pool corresponded to one independent experiment; A)- Antioxidant response (Cat); B)-Hypoxia (Epas1); C) Chondrocyte catabolism- (Mmp3, Mmp13 and Adamts5). Statistical analysis was done by Two-way ANOVA followed by Tukey multiple comparison test with $\mathrm{p}<0.05$; Statistical significance: (a)- compared to control [Na-Cit]; (b)- compared to [Fe-Cit $10 \mu \mathrm{M}]$ ); (*)comparison between WT and Hfe-KO cells subject to [Fe-Cit $50 \mu \mathrm{M}$ ].

Figure 4- Expression of genes associated with chondrocyte metabolism. Expression of A)-Markers for chondrocyte anabolism (Colla1, Col10al and Acan); and B)-Markers for transdifferentiation (Bglap2, Sox9 and Trf), were analysed in WT and Hfe-KO chondrocytes after 7 days in culture treated with either $10 \mu \mathrm{M}$ or $50 \mu \mathrm{M}$ ferric citrate, or in vehicle ([Na-Cit $])$; Results are from $n=5$ pools of three cell culture wells $\left(9.6 \mathrm{~cm}^{2}\right)$ for each genotype (WT and Hfe-KO).Each pool corresponded to one independent experiment. All results were normalized by Gapdh and statistical analysis was done by Two-way ANOVA followed by Tukey multiple comparison test with $p<0.05$; Statistical significance: (a)- compared to control [Na-Cit]; (b)- compared to [Fe-Cit $10 \mu \mathrm{M}]$ ); For Bglap2 expression WT groups did not show a normal distribution, therefore multiple comparison between treatments WT chondrocytes was done by Kristal-Wallis method and multiple comparison with Dunn's post-hoc test. For Hfe-KO chondrocytes One-way ANOVA was used to compare the impact of treatments with control, with Tukey test for post-hoc multiple comparison with $\mathrm{p}<0.05$. 
Figure 5- Evaluation of extracellular matrix degradation in WT and Hfe-KO chondrocytes. A) Comparison of Alcian blue staining relative pixel intensity in chondrocytes treated with $50 \mu \mathrm{M}$ of ferric citrate relative to vehicle ([Na-Cit]. B) WT and Hfe-KO chondrocytes stained with Alcian blue. Statistical analysis was done by T-test, with $\mathrm{p}<0.05$. Statistical significance: (a)- compared to control [Na-Cit]. C)- Levels of MMP3 in WT and Hfe-KO chondrocytes cultured for 10 days detected by Western blot and peroxidase chemiluminescent signals compared to levels of beta actin as described in materials and methods section. Results correspond to the levels of protein from a pool of wells obtained from three independent experiments.

Figure 6-Expression of MMP3 and ADAMTS5 in WT and Hfe-KO mice subject to knee destabilization. A- Articular cartilage integrity analysis. Evaluation of knee articular cartilage integrity detected through OARSI score in WT (Sham and MNX) and Hfe-KO (Sham and MNX) mice. $(n=10)$. Results described are a result of the summed OARSI score average between the three levels evaluated in the articular cartilage of each mice by two independent observers. The associated error is the confidence interval at $95 \%$. Statistical analysis was done by Two-way ANOVA, followed by Tukey multiple comparison test with $\mathrm{p}<0.05$ for each group analysed (WT sham, WT MNX, Hfe-KO Sham and Hfe-KO MNX) in tibia and femur. Comparisons between tibia and femur results were done by Paired T-test with $\mathrm{p}<0.05$ for significance. a) statistical significance with $p<0.05$ between Sham and MNX groups within each genotype. b) Statistical significance between WT MNX and Hfe-KO MNX with $\mathrm{p}<0.05$. $*$ Statistical significance between tibia and femur with $\mathrm{p}<0.05$. B- Detection of disintegrin and metallopeptidase with thrombospondin motifs (ADAMTS-5) and matrix metallopeptidase 3 (MMP-3) in articular cartilage.- Immunohistochemistry for knee articular cartilage in tibia of control (WT MNX) and Hfe-KO (Hfe-KO MNX) mice at 8 weeks after MNX surgery. ADAMTS5 and MMP3 detection was done with DAB Kit SK4100 and correspond to brown staining. Counterstaining was done with $1 \%$ methyl green, which stains hyaline cartilage tissues. The comparison between WT and Hfe-KO showed higher degree of ADAMTS5 and MMP3 detection in Hfe-KO mice relative to WT. 
A)

B)
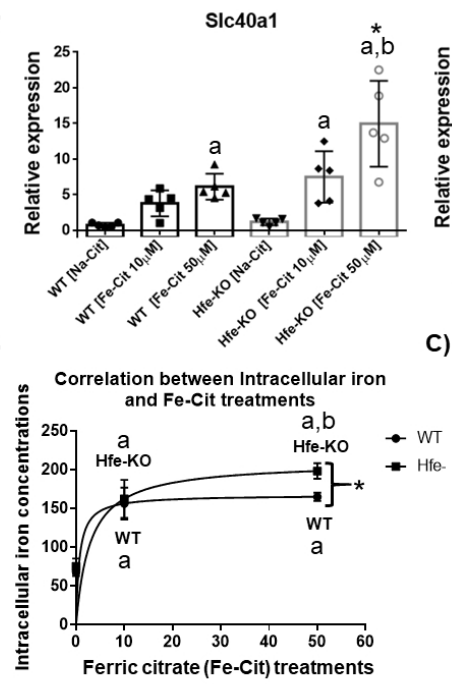

Fth1

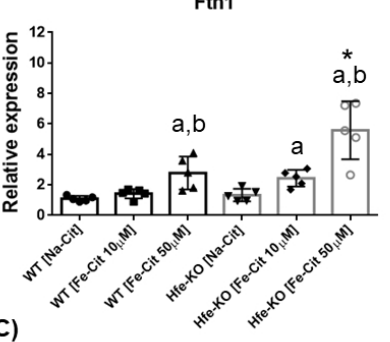

Tfr2

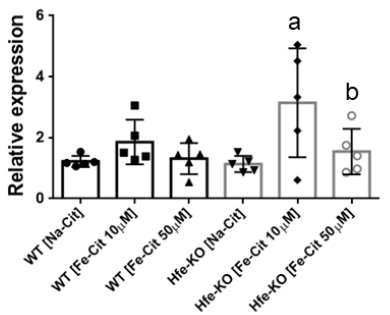

Tfrc

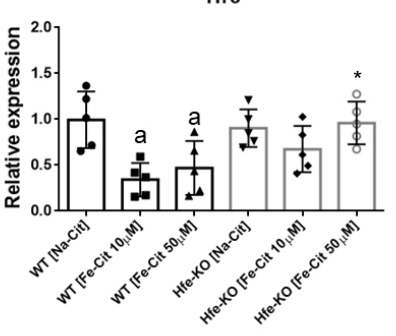

SIc39a14

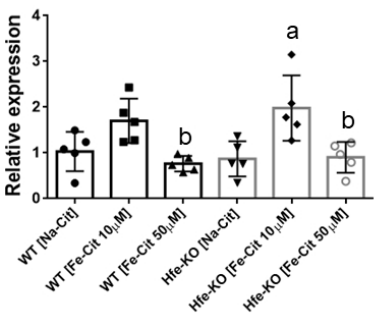

Figure 1- Expression of genes associated with iron metabolism in Hfe-KO and WT chondrocytes cultured under iron overload conditions (Genes: Solute Carrier Family 40 Member 1 (Slc40a1), also known as ferroportin, Ferritin Heavy Chain 1 (Fth1), solute carrier family 39 (zinc transporter) member 14 (Slc39a14), Transferrin receptor 1 (Tfrc) and Transferrin receptor 2 (Tfr2)). Cells were cultured for 7 days in the presence of either $10 \mu \mathrm{M}$ or $50 \mu \mathrm{M}$ of ferric citrate, or vehicle ([Na-Cit]). Results shown correspond to relative expression normalized with Gapdh from $n=5$ pools of three cell culture wells $(9.6 \mathrm{~cm} 2)$ for each genotype (WT and Hfe-KO). Each pool corresponded to an independent experiment; A)-Intracellular iron markers (Slc40a1, Fth1 and Tfrc), B)- Correlation between measured intracellular iron concentrations and levels of ferric citrate treatments applied to WT and Hfe-KO chondrocytes. Each condition corresponded to data from $n=3$ samples and were expressed as mean +/- standard deviation (SD). (C)- Iron transporters (Tfr2, Slc39a14); Statistical analysis was done by Two-way ANOVA, followed by Tukey multiple comparison test with $\mathrm{p}<0.05$. Statistical significance: (a)- compared to control [Na-Cit]; (b)- compared to [Fe-Cit 10 $\mu \mathrm{M}]) ;(*)$ - comparison between WT and Hfe-KO cells subject to [Fe-Cit $50 \mu \mathrm{M}$ ]. 



Figure 2-Articular cartilage integrity analysis and iron status in Hfe-KO mice A- Evaluation of knee articular cartilage integrity through OARSI score of WT and Hfe-KO mice with 12 months of age (male $(n=7)$ and female $(n=4)$ ) and examples of articular cartilage phenotype in $5 \mu \mathrm{m}$ sagittal sections of WT and Hfe-KO mice stained with Haematoxylin-Fast Green-Safranin-O staining. $\left({ }^{*}\right)$ Statistical significance with $p<0.05$. Comparison was made T-test within each genotype B- Total serum iron quantification from WT and Hfe-KO male mice with 12 months of age. C- Perls staining of undecalcified tissues sagittal sections $(5 \mu \mathrm{m})$ of articular cartilage included in Methyl methacrylate (MMA). Iron deposition shown by dark blue staining. 


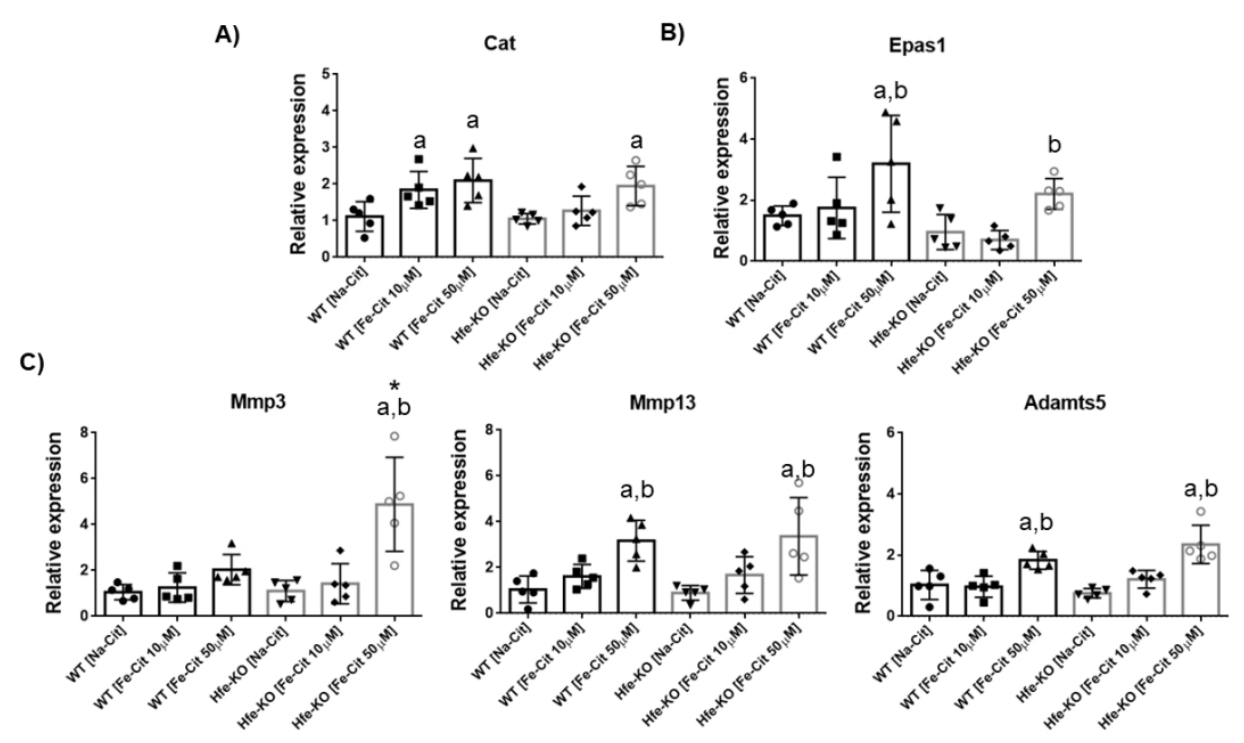

Figure 3- Expression of genes associated with antioxidant response, hypoxia and markers associated with chondrocyte catabolism. Hfe-KO and WT chondrocytes were subjected to treatments for 7 days with either $10 \mu \mathrm{M}$ or $50 \mu \mathrm{M}$ of ferric citrate, or vehicle ([Na-Cit]). Results were normalized with Gapdh from $n=5$ pools of three cell culture wells $(9.6 \mathrm{~cm} 2)$ for each genotype (WT and Hfe-KO). Each pool corresponded to one independent experiment; A)- Antioxidant response (Cat); B)-Hypoxia (Epas1); C) Chondrocyte catabolism(Mmp3, Mmp13 and Adamts5). Statistical analysis was done by Two-way ANOVA followed by Tukey multiple comparison test with $\mathrm{p}<0.05$; Statistical significance: (a)- compared to control [Na-Cit]; (b)- compared to [Fe-Cit $10 \mu \mathrm{M}$ ]); (*)- comparison between WT and Hfe-KO cells subject to [Fe-Cit $50 \mu \mathrm{M}$ ]. 
A)
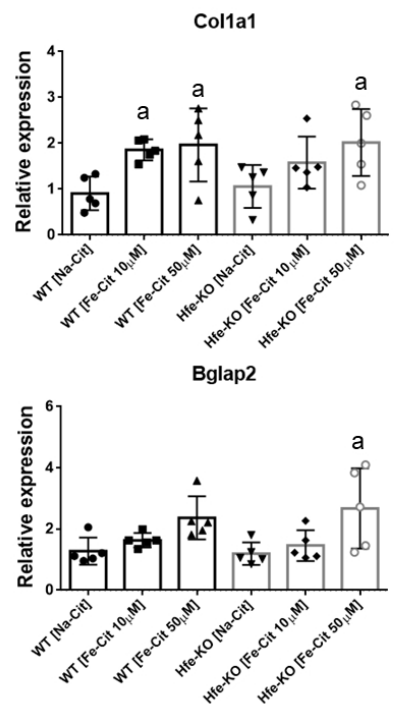

Col10a1
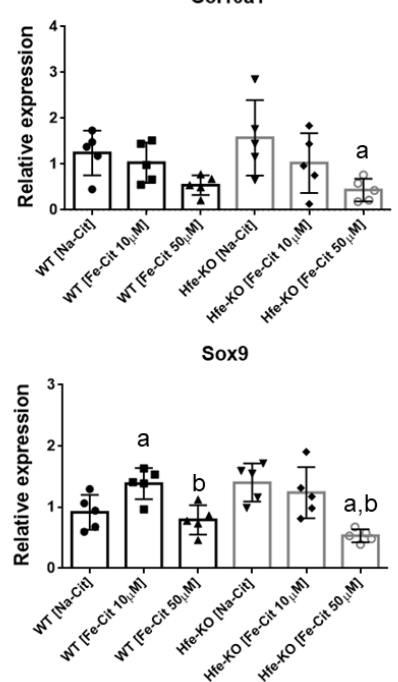

Acan
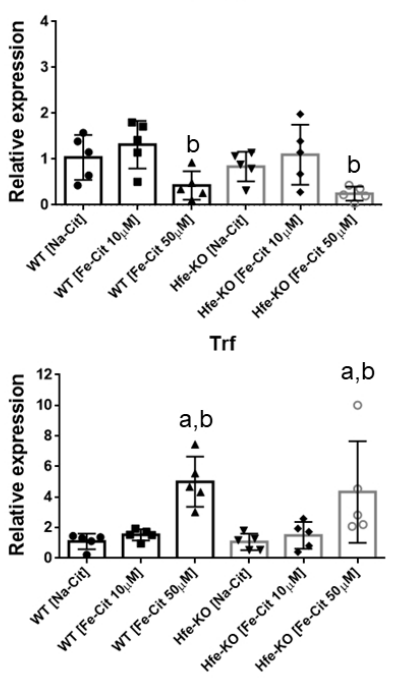

Figure 4- Expression of genes associated with chondrocyte metabolism. Expression of A)-Markers for chondrocyte anabolism (Col1a1, Col10a1 and Acan); and B)-Markers for transdifferentiation (Bglap2, Sox9 and Trf), were analysed in WT and Hfe-KO chondrocytes after 7 days in culture treated with either $10 \mu \mathrm{M}$ or $50 \mu \mathrm{M}$ iron citrate, or in vehicle ([Na-Cit]); Results are from $\mathrm{n}=5$ pools of three cell culture wells $(9.6 \mathrm{~cm} 2)$

for each genotype (WT and Hfe-KO). Each pool corresponded to one independent experiment. All results were normalized by Gapdh and statistical analysis was done by Two-way ANOVA followed by Tukey multiple comparison test with $\mathrm{p}<0.05$; Statistical significance: (a)- compared to control [Na-Cit]; (b)- compared to

[Fe-Cit $10 \mu \mathrm{M}]$ ); For Bglap2 expression WT groups did not show a normal distribution, therefore multiple comparison between treatments WT chondrocytes was done by Kristal-Wallis method and multiple comparison with Dunn's post-hoc test. For Hfe-KO chondrocytes One-way ANOVA was used to compare the impact of treatments with control, with Tukey test for post-hoc multiple comparison with $p<0.05$. 


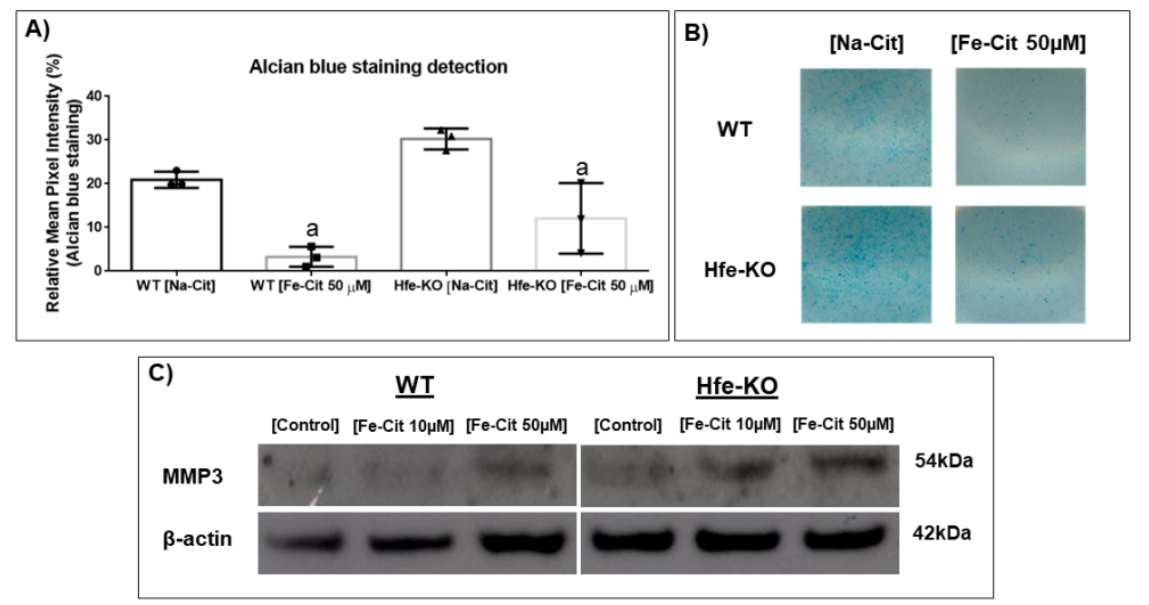

Figure 5- Evaluation of extracellular matrix degradation in WT and Hfe-KO chondrocytes. A) Comparison of Alcian blue staining relative pixel intensity in chondrocytes treated with $50 \mu \mathrm{M}$ of iron citrate relative to vehicle ([Na-Cit]. B) WT and Hfe-KO chondrocytes stained with Alcian blue. Statistical analysis was done by T-test, with $\mathrm{p}<0.05$. Statistical significance: (a)- compared to control [Na-Cit]. C)- Levels of MMP3 in WT and $\mathrm{Hfe}-\mathrm{KO}$ chondrocytes cultured for 10 days detected by Western blot and peroxidase chemiluminescent signals compared to levels of beta actin as described in materials and methods section. Results correspond to the levels of protein from a pool of wells obtained from three independent experiments. 


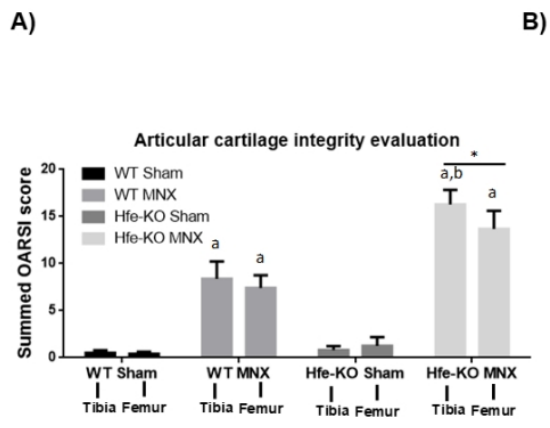

B)

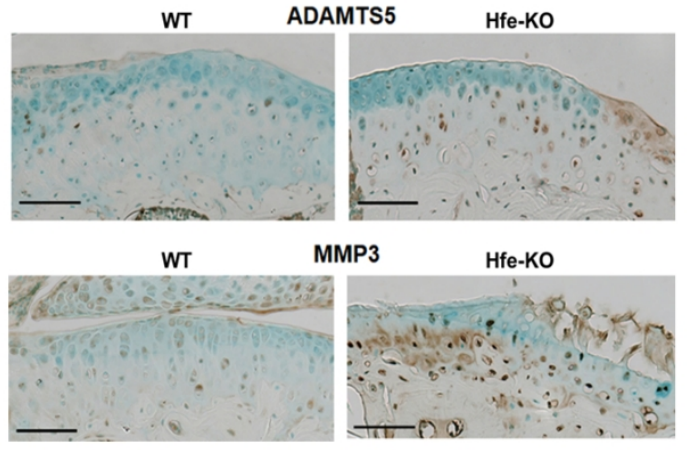

Figure 6-Expression of MMP3 and ADAMTS5 in WT and Hfe-KO mice subject to knee destabilization. AArticular cartilage integrity analysis. Evaluation of knee articular cartilage integrity detected through OARSI score in WT (Sham and MNX) and Hfe-KO (Sham and MNX) mice. $(n=10)$. Results described are a result of the summed OARSI score average between the three levels evaluated in the articular cartilage of each mice by two independent observers. The associated error is the confidence interval at $95 \%$. Statistical analysis was done by Two-way ANOVA, followed by Tukey multiple comparison test with $\mathrm{p}<0.05$ for each group analysed (WT sham, WT MNX, Hfe-KO Sham and Hfe-KO MNX) in tibia and femur. Comparisons between tibia and femur results were done by Paired T-test with $p<0.05$ for significance. a) statistical significance with $\mathrm{p}<0.05$ between Sham and MNX groups within each genotype. b) Statistical significance between WT

MNX and Hfe-KO MNX with $\mathrm{p}<0.05$. * Statistical significance between tibia and femur with $\mathrm{p}<0.05$. B-

Detection of disintegrin and metallopeptidase with thrombospondin motifs (ADAMTS-5) and matrix metallopeptidase 3 (MMP-3) in articular cartilage.- Immunohistochemistry for knee articular cartilage in tibia of control (WT MNX) and Hfe-KO (Hfe-KO MNX) mice at 8 weeks after MNX surgery. ADAMTS5 and MMP3 detection was done with DAB Kit SK4100 and correspond to brown staining. Counterstaining was done with $1 \%$ methyl green, which stains hyaline cartilage tissues. The comparison between WT and Hfe-KO showed higher degree of ADAMTS5 and MMP3 detection in Hfe-KO mice relative to WT. 